\author{
Sustinere \\ Journal of Environment and Sustainability \\ Volume 4 Number 2 (2020) 117-131 \\ Print ISSN: 2549-1245 Online ISSN: 2549-1253 \\ Website: https://sustinerejes.com E-mail: sustinere.jes@iain-surakarta.ac.id
}

\title{
RESEARCH PAPER \\ Plate and faults boundary detection using gravity disturbance and Bouguer gravity anomaly from space geodesy
}

\author{
Atriyon Julzarika*1,2, Argo Galih Suhadha1, Indah Prasasti1 \\ ${ }^{1}$ Indonesian National Institute of Aeronautics and Space (LAPAN), Indonesia \\ ${ }^{2}$ Dept. of Geodesy Geomatics Engineering, Universitas Gadjah Mada (UGM), Indonesia \\ Article history: \\ Received 22 May 2020 | Accepted 19 August 2020 | Available online 29 August 2020
}

\begin{abstract}
Nowadays, satellite technology has developed significantly. Geodesy satellites such as Grace and Grace-FO can be used for subsurface mapping. The mapping is in the form of detection of the plate details, faults, and regional geodynamic conditions. This study aims to detect plate and faults from space geodesy using the gravity disturbance and Bouguer gravity anomaly parameter. The study area is in the Sunda Strait. Gravity disturbance is one of the gravity model parameters. Gravity disturbance is the gravitational potential of the topography expressed by the spherical harmonic model and the topographic effect by Barthelmes's calculations. Gravity disturbance can visualize subsurface conditions. Bouguer gravity anomaly is needed to get the condition on subsurface objects. This parameter visualizes subsurface conditions in the form of rocks and non-rocks. These conditions can distinguish oceanic crust and continental crust. Gravity contours are needed to obtain plate and faults predictions. The results obtained are validated patterns and shapes with plate and faults secondary data. The tolerance used in this validation is $80 \%$. The gravity disturbance parameter obtained a value of $83 \%$ in verifying the accuracy of assessment in plate and faults detection. The Bouguer gravity disturbance parameter obtained a verification value of accuracy assessment in plate detection but $65 \%$ in faults detection. This accuracy assessment uses pattern and texture parameters in detecting the similarity of two or more images. This plate and faults detection results are more detailed and can be used for geophysical, geological, earthquake, and earth dynamics applications.
\end{abstract}

Keywords: plate and faults, Sunda Strait, gravity disturbance, space geodesy

\section{Introduction}

Geodynamics plays a role in explaining the history of the earth formation, changes, continents and oceans re-creation, geological formation, mountain ranges, and river valleys (Turcotte \& Schubert, 2014). Geodynamics includes the hydrocarbon reserves and all minerals contained in the Earth. Geodynamics aims to explain conceptually about the process of tectonic formation, the combination of heat and earth mechanical explanation (Turcotte \& Schubert,

${ }^{*}$ Corresponding author. E-mail: verbhakov@yahoo.com
DOI: https://doi.org/10.22515/sustinere.jes.v4i2.108 
2014). The geodynamics can be divided into energy, kinetic, and Earth dynamics goals on energy objectives, including the distribution of heat energy related to the Earth's temperature (Hofmann-Wellenhof \& Moritz, 2006). The kinetic in geodynamics includes the use of velocity and stress parameters.

The purpose of dynamics is to discuss the contribution of several applications to geodynamic processes in the outermost layers and the earth's crust (Turcotte \& Schubert, 2014). Generally, the purpose of geodynamics is to know geological deformations, predict continental patterns, and to understand the mechanism of earth plate tectonic movements that function in explaining seismicity that occurs on Earth. The tectonic system is a system that involves shifting the lithosphere (Turcotte \& Schubert, 2014). The lithosphere is divided into a mosaic of separate plates (McKenzie \& Priestley, 2016). These plates themselves shift to separate themselves that can collide with each other and bump into each other.

The margins of the plate boundaries are the geological activity that occurs, such as seafloor spreading, continental rifting, mountain formation, volcanic activity, and earthquakes (Turcotte \& Schubert, 2014). One part of geodynamics is deformation. Deformation can be extracted from the geodetic survey, aerial survey, and space geodesy (Devanthéry et al., 2016). Deformation is related to change in position caused by gravity anomaly. Relative deformation occurs when motion is assessed from another point. Changes in position or movement of points generally refer to specific systems and reference fields (absolute or relative) (Lanari et al., 2004). Deformation can be monitored by mapping on the surface and sub-surface of the earth (Monserrat et al., 2014). The changing position in the sub-surface is caused by the deformation of shift and strain (Szostak-Chrzanowski, 2006). This deformation occurs in regions with high and low voltage geodynamics. High deformation generally occurs in areas that have faults and plate using gravity modeling for subsurface mapping (Venera et al., 2016). This research focuses on geodynamics due to natural phenomena. The geometrical analysis is needed to detect the plate and faults by using the gravity anomaly approach.

Gravity anomalies that occur in these plates and faults are influenced by surface and crustal deformations in the region (Turcotte \& Schubert, 2014). Mapping of the plate and faults can be done using three methods, namely Leveling, Global Navigation Satellite System (GNSS), and Space Geodesy. The use of these three methods is adjusted to the conditions of the area and accuracy-precision requirement. This deformation mapping includes surface deformation, crustal deformation, land subsidence, plate, fault, seismic, landslide, and liquefaction (Sansosti et al., 2010). The leveling method will yield sub-millimeter accuracy (Serrano-Juan et al., 2017). This very high vertical accuracy is due to the measurement in a small territory, and it is easier to correct the measurement results. The Leveling method has the disadvantage of high measurement costs and less extensive area coverage (Serrano-Juan et al., 2017). The GNSS method has the advantage of not being limited by distance, and the measurement cost is relatively cheap than Leveling (Leick et al., 2015). The GNSS method has the disadvantage of being difficult to correct errors in height difference measurements (Leick et al., 2015). Even though GNSS can take measurements without distance restrictions, these measurements only produce one point for each measurement (Serrano-Juan et al., 2017).

Space Geodesy includes gravity anomaly modeling and Differential Interferometry Synthetic Aperture Radar (DInSAR). It has the advantage of measuring multiple points over a 
large spatial area. The measurement of space Geodesy results is focusing on high precision (Sansosti et al., 2010). Gravity anomaly modeling focused on precision but low accuracy (Sansosti et al., 2010). Gravity anomaly modeling can be used to visualize in sub-surface and can measure in dense vegetation. DInSAR is used to visualize the surface. DInSAR measurement accuracy is similar to measurements made by GNSS, depending on the character of the area being measured. The measurement cost with DInSAR is cheaper than GNSS-Leveling (SerranoJuan et al., 2017). The weakness of the Space Geodesy method is that it has lower vertical accuracy compared to Leveling. Another weakness of DInSAR is that the measurement of dense vegetation depends on the type of band used in the SAR data used (Julzarika, 2015). L band will produce higher vertical accuracy than $\mathrm{C}$ and $\mathrm{X}$ band. $\mathrm{C}$ band has higher vertical accuracy than the $\mathrm{X}$ band.

In this study, the Space Geodesy (gravity anomaly modeling) method was chosen because it can be used for regional mapping, sub-surface mapping, and is low cost. The research area is located in the Sunda Strait and includes a large area and requires high costs if it is carried out with GNSS-Leveling. This area has more sea area than land, so it is more optimal with subsurface mapping than DInSAR mapping. The Sunda Strait region is a region with high deformation (Lasitha et al., 2006). The Sunda Strait is a strait that connects the Java and Sumatra islands in Indonesia and connects the Java Sea with the Indian Ocean. High deformation is the deformation that occurs in the tectonic region at the junction of plates, faults, and folds and areas with high geodynamics (Turcotte \& Schubert, 2014). High deformation also occurs in active volcanic regions (Grilli et al., 2019). Other areas that are the focus of high deformation are occurring in areas of high ground movement and areas of potential liquefaction.

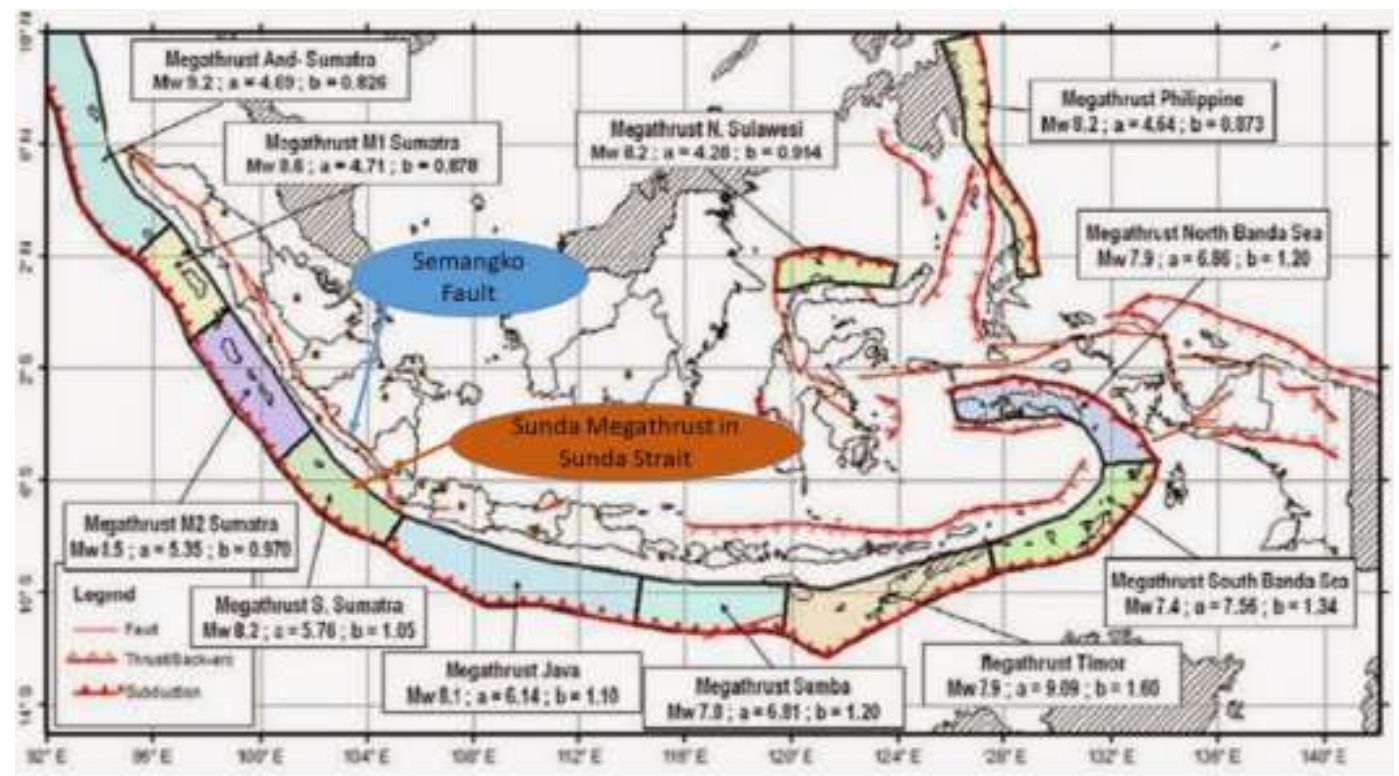

Figure 1. The location of Sunda Megathrust and Semangko Fault. It is modified from the faults map of BMKG (2020).

Generally, high deformation will experience high dynamics or changing of subsurfaces by gravity anomaly (gravity disturbance and Bouguer gravity anomaly) (Drewes et al., 2016). Sunda Megathrust is a fault that extends from Myanmar-southwest Sumatra-south Java to Bali and ends in northern Australia. Sunda Megathrust has a length of around 5,500 km. Sunda 
Megathrust is located on the convergent plate boundary (Natawidjaja, 2018), see Figure 1 Sunda Megathrust is located on the Eurasian plate, which overwrites and the Indo-Australian plate subduction; it is a seismogenic structure. These faults are divided into Andaman Megathrust, Sumatra Megathrust, and Java Megathrust.

The Semangko Fault is a geological formation that runs along the Sumatra island, Indonesia (Julzarika \& Harintaka, 2019). This fault stretches from Aceh to Semangko Bay. This fault forms the Bukit Barisan. The Semangko Fault is a sliding fault, relatively young, and often experiences a massive earthquake, and it is part of the Eurasian Plate (Continental) (Alifa et al., 2020). This fault was formed when the Indo-Australian plate (oceanic) crashed into the Eurasian plate (continental) (Hurukawa et al., 2014). This collision triggers the emergence of two forceful components and causes a gravity anomaly to occur subsurface.

This research paper is focused on the use of gravity disturbance and Bouguer gravity anomaly in plate and faults detection in the Sunda Strait. During this time, monitoring of faults and gravity around the Sunda Strait was carried out by field and airborne surveys. The novelty of this research is using the gravity model from space geodesy to detect the plate and faults in Sunda Strait. This study aims to detect plate and faults in the Sunda Strait with gravity models from space geodesy.

\section{Literature review}

\subsection{Gravity disturbance}

The geoid is the real earth model or equipotential plane which coincides with the sea surface when it is calm and without disturbances (Bayoud \& Sideris, 2003). Practically, the geoid is considered to coincide with Mean Sea Level (MSL) (Hofmann-Wellenhof \& Moritz, 2006). The distance of the ellipsoid to the geoid is called the geoid undulation $(\mathrm{N})$, see Figure 2. Geoid undulation is the difference of ellipsoidal height from the orthometric height (Drewes et al., 2016). The value of the geoid undulation is not similar in all places, and this is due to the uneven distribution of Earth's mass density (Georges Balmino \& Bonvalot, 2016; Bonvalot et al., 2012). Geoid with high accuracy is needed for geodesy, geophysics, geological, and oceanography applications (Hirt et al., 2012).

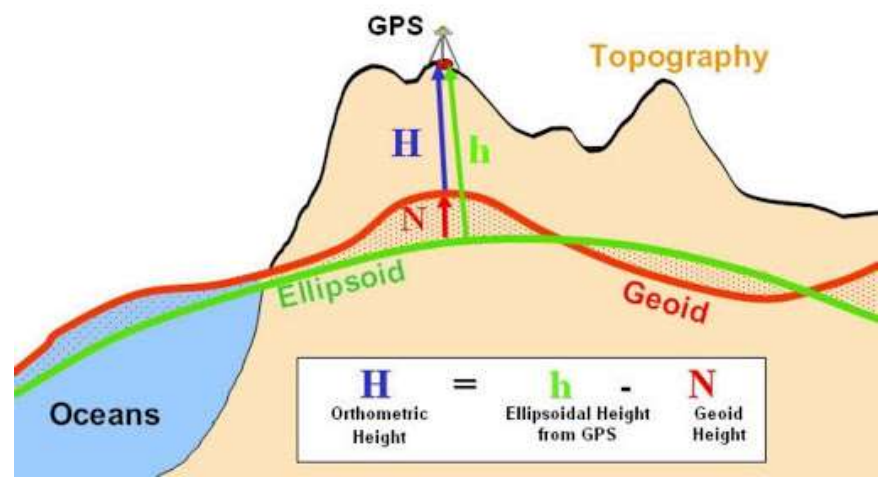

Figure 2. Geoid undulation (Drewes et al., 2016) 
Gravity model parameter includes free air, gravity disturbance, Bouguer gravity anomaly, and isostatics (Hirt et al., 2012). In this study, the gravity model used is gravity disturbance and Bouguer gravity anomaly. The harmonic expansion coefficient of the spherical gravity field is a parameter for gravitational potential (Balmino et al., 2012). The gravitational disturbance is defined as the topographic gravitational potential expressed in spherical harmonic expansion, topographic effects (Hutchinson \& Gallant, 2000), and calculated by physical geodesy equations (Barthelmes, 2013, 2014), see equation (1).

$$
\begin{aligned}
\delta_{g}(r, \vartheta, \lambda) & =-\frac{\partial T(r, \vartheta, \lambda)}{\partial r} \\
& =\frac{G M}{r^{2}} \sum_{n=0}^{N} \sum_{l=0}^{n}\left(\frac{a}{r}\right)^{n}(n+1)\left(\Delta C_{n l} \operatorname{Cos} l \lambda+\Delta S_{n l} \sin l \lambda\right) P_{n l}(\cos \vartheta)
\end{aligned}
$$

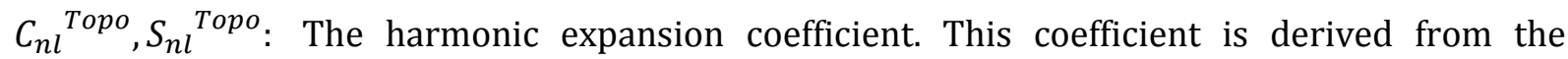
gravitational potential of the topographic mass (Doğru \& Pamukçu, 2019).

The Bouguer field is calculated by a global model expressed in the spherical harmonic expansion of the field observed and the field generated from topographic and bathymetric masses (Claessens \& Hirt, 2013; Hirt \& Kuhn, 2012; Raaflau \& Collins, 2006). Gravity modeling can be done by 3D interpolation (Fukuda et al., 2016; Ince et al., 2019). These interpolations can be Kriging, CoKriging, Spline, and natural neighbor (Ledoux \& Gold, 2005; Li \& Kuai, 2014). In addition, modeling can also be done with a surface roughness approach (Hani et al., 2011; Yue et al., 2007). Besides, the modeling can also be done with a surface roughness approach (Hanssen, 2002).

\subsection{Grace and Grace-FO}

One of the space geodesy technologies is the Gravity Recovery and Climate Experiment (GRACE) satellite (see Figure 3). GRACE is a satellite of research collaboration between the University of Texas, the National Aeronautics and Space Administration (NASA), Deutsches Zentrum für Luft und Raumfahrt (DLR), the GeoForschungsZentrum (GFZ), and Jet Propulsion Laboratory (JPL) (NASA, 2018). The GRACE satellite is a satellite for monitoring gravity, climate experiments, investigations of Earth reservoirs, land, ice, and oceans (Ince et al., 2019). The GRACE satellite is a twin satellite. This satellite has been operating from 2002 to 2017 (ESA, 2020).

GRACE measures the gravity field. The way to do this is to connect it with the distance between the twin satellites (NASA, 2018). Gravity increase will make the first satellite accelerated, and the distance between the pairs increases. The distance between satellites will decrease when there is an increase of the gravity between pairs. Both satellites have a distance of $220 \mathrm{~km}$ and can detect changes smaller than a micrometer per second in relative speed. This satellite can also take measurements together with other gravity satellite data and models. The results obtained will provide observations on changes in terrestrial water storage, variations in ice mass, changes in seabed pressure, and variations in sea level (ESA, 2020).

The Gravity Recovery and Climate Experiment Follow (GRACE-FO) is a continuation satellite of GRACE (NASA, 2018). This satellite was developed with a collaborative research partnership between NASA and GFZ, which was launched on May 22, 2018 (NASA, 2018). These twin satellites can map variations in the Earth's gravitational field accurately. It also can map the 
distribution of mass fields and surface gravity. GRACE-FO consists of two identical satellites that fly an initial altitude of about $490 \mathrm{~km}$ and a nominal separation distance of $220 \pm 50 \mathrm{~km}$ (ESA, 2020). The Grace-FO satellite instrument can measure precisely the changes between the two satellites caused by orbital interference. This disturbance is caused by geographical and temporal variations in the Earth's gravitational field.

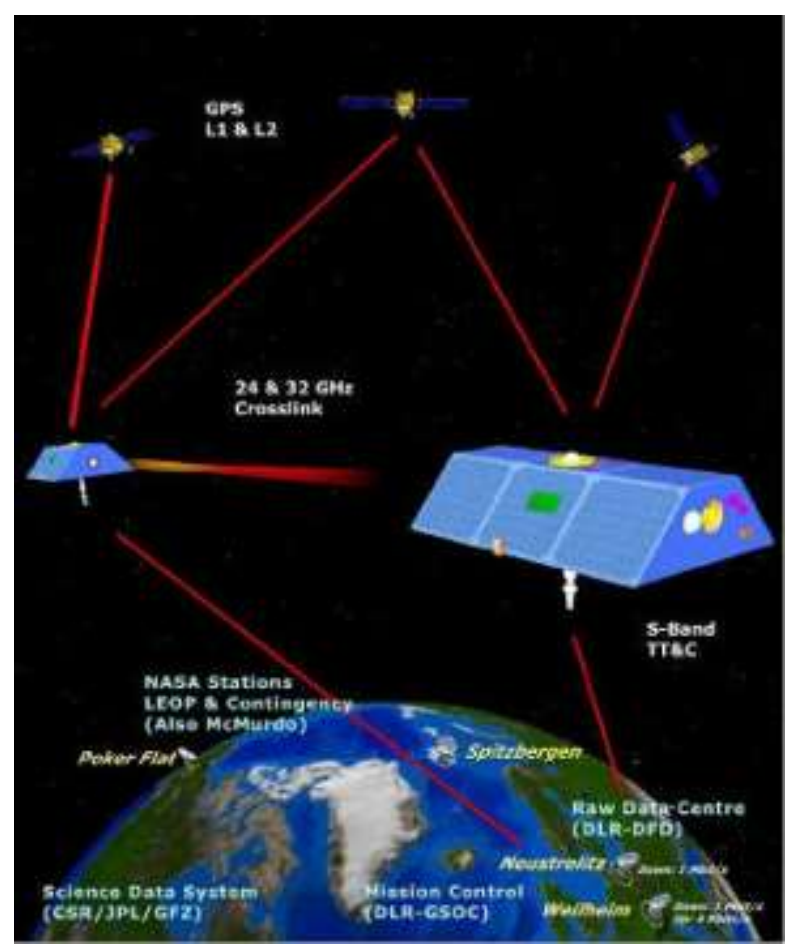

Figure 3. GRACE satellite measurement, retrieved from ESA, 2020

GRACE-FO can expand the greatness of the previous GRACE satellites in tracking mass changes in monitoring changes in deep ocean currents, driving forces in climate, and even measuring changes in a dense Earth. Changes in this Earth include post-racial rebounding, the impact of large earthquakes, monitoring of plates, and faults with the Earth's gravitational plane approach (ESA, 2020; NASA, 2018),

\section{Methodology}

\subsection{Research area}

The study area of this research was Sunda strait. Sunda strait is located between Lampung Province and Banten Province with longitude at $104^{\circ} 04^{\prime} 06.9089^{\prime \prime}$ E to $106^{\circ} 22^{\prime} 06.8896^{\prime \prime}$ E and latitude at $5^{\circ} 38^{\prime} 59.0455^{\prime \prime} \mathrm{S}$ to $8^{\circ} 01^{\prime} 35.7529^{\prime \prime} \mathrm{S}$. The study area is presented in Figure 4.

\subsection{Data}

The data used were Grace from 2002 to 2017, while Grace-FO data were used in 2018. Data was obtained from Bureau Gravimétrique International (BGI), International Centre for Global Earth Models- GeoForschungsZentrum (GFZ), and NASA. Gravity disturbance is extracted from Grace and Grace-FO data. The secondary data is the geological structure from the United States for Geological Survey (USGS) and the Ministry of Energy and Mineral Resources. 


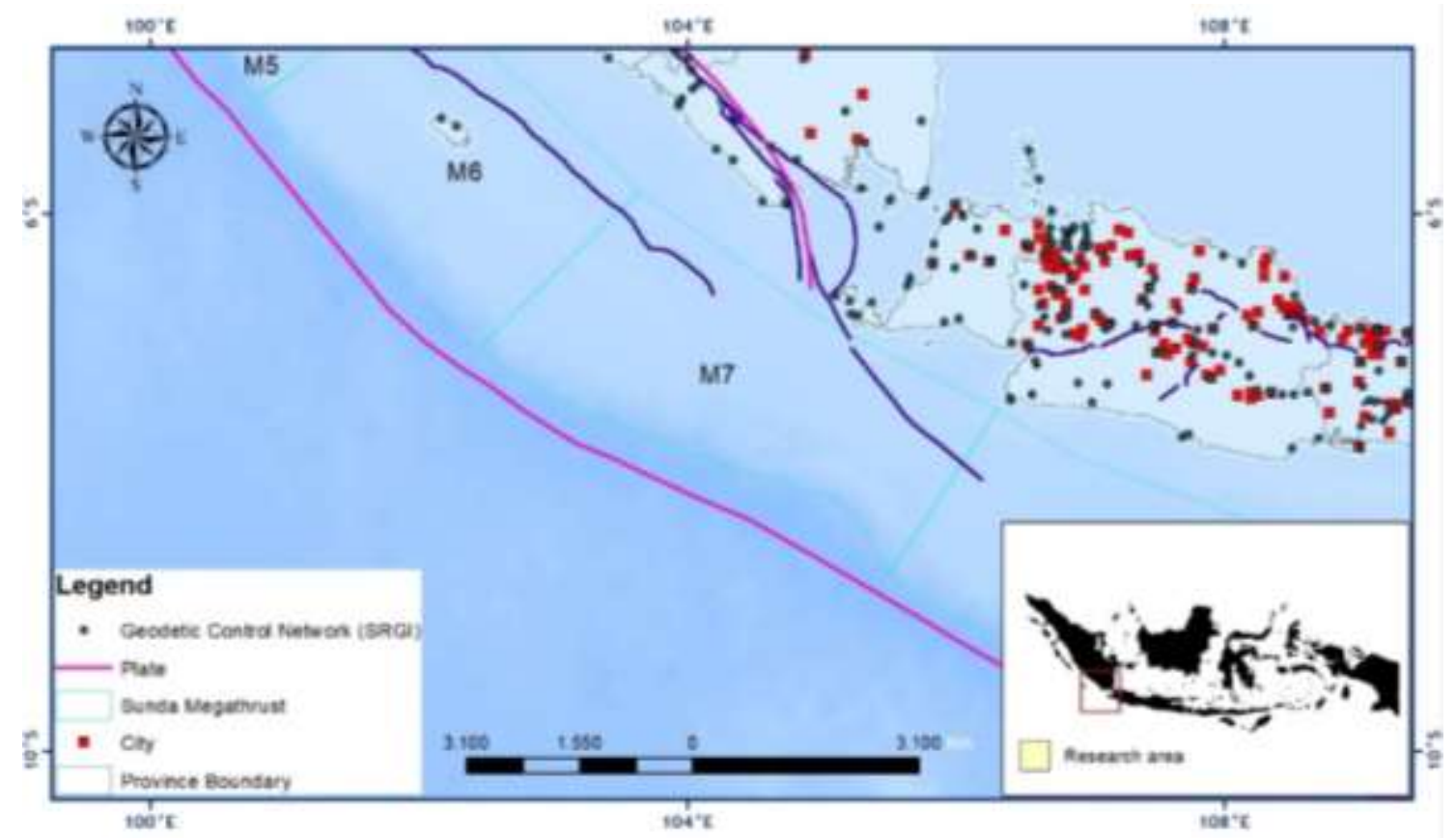

Figure 4. Sunda strait location. Rex box is the study area.

\subsection{Research procedure}

This study uses a flow chart in Figure 5. The data used is a combination of Geodesy satellite: Grace and Grace-FO data. Both data are carried out on data integration. It aims to get more detailed information in the study area. The integration produced data from 2000 to 2018 . In geological studies, information every 300 years can be used for medium-scale geological mapping. Then the data that has been integrated is carried out by gravity disturbance extraction. The extraction uses the Barthelmes equation. Gravity disturbance is useful to know the geodynamic conditions of subsurfaces. These conditions can determine the level of gravity density in various subsurface objects after that anomaly Bouguer gravity extraction is done.

This parameter is useful in mapping subsurface conditions, whether in the form of rock or non-rock. The condition of these non-rocks can be used to determine the oceanic and continental crust. The process carried out is gravity contours extraction based on gravity disturbance and Bouguer gravity anomaly. The results obtained are the results of the temporary detection of plate and faults based on gravity contours. This result needs to be validated with an available plate and fracture data obtained from the United States Geological Survey (USGS) and the Ministry of Energy and Mineral Resources. The shape of the plate lines and faults extracted from gravity disturbance is more detailed and has a more extensive map scale. The secondary data is only used for form validation, plate patterns, and faults. The validation uses the similarity of two vector files, and we use tolerance in its similarity in $60 \%$. Iteration of gravity disturbance will be done if it does not meet the validation results. The plate and faults are obtained after this validation. 


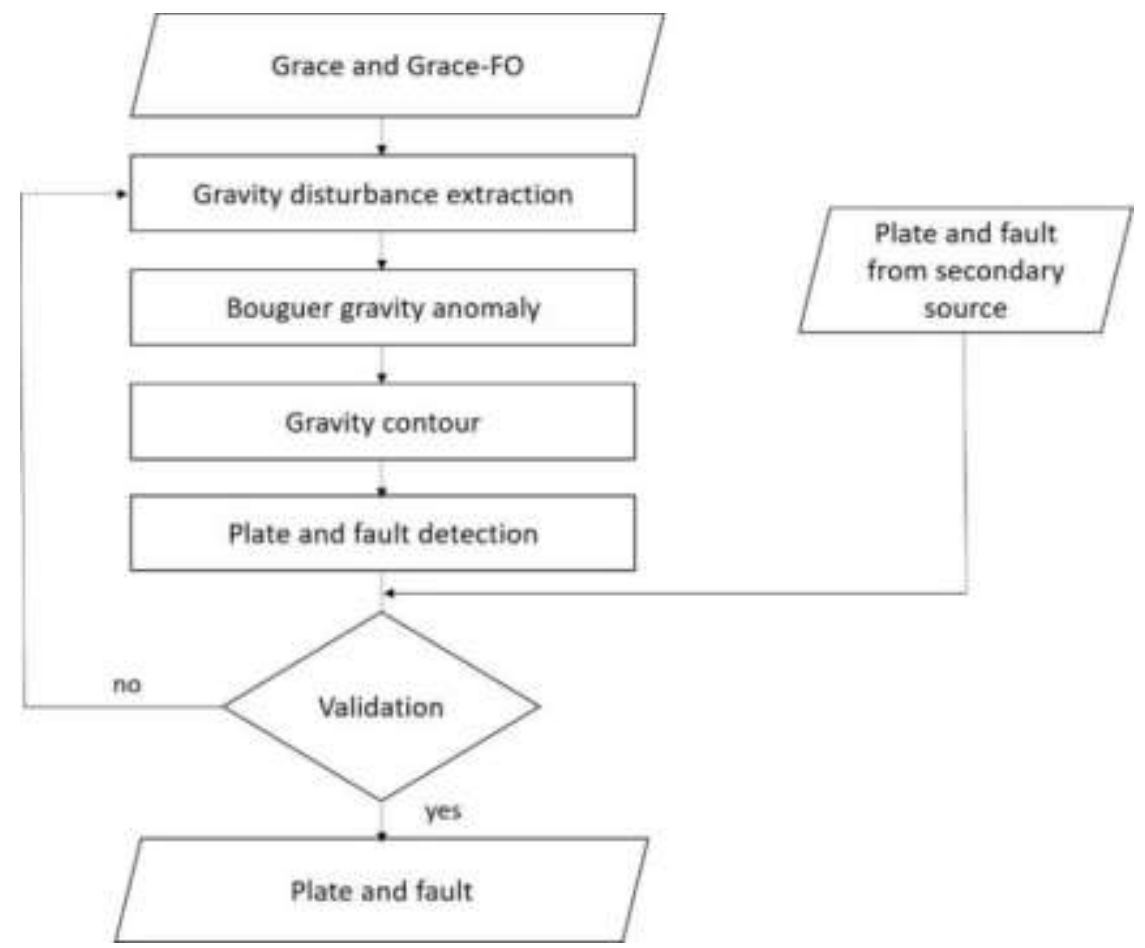

Figure 5. Research methodology flowchart

\subsection{Verification using similarity data}

The similarity is the measure of the minimum two data on how much alike are. A similarity measure is a data mining concept. It is a distance with dimensions representation feature of the objects. It will be a high degree of similarity if the distance is small. This research is using the tolerance of the distance in $60 \%$ or 0.6 . The normalization must be done to get the relative values of each element. It is the one feature that could end up dominating the distance calculation. Similarity is measured in the range 0 to $1[0,1]$. Two main considerations of similarity:

$$
\begin{aligned}
& \text { Similarity }=1 \text { if } X=Y \quad \text { (Where } X, Y \text { are two objects) } \\
& \text { Similarity }=0 \text { if } X \neq Y
\end{aligned}
$$

\section{Results}

\subsection{Gravity anomaly extraction}

The gravity disturbance visualizes the gravity anomaly conditions that occur in the Sunda Strait. Its extraction can cover land and ocean areas. This condition is caused by the gravity disturbance visualization of subsurface conditions. The results of this gravity disturbance extraction can be seen in Figure 6.

This gravity disturbance value is located in the range of values -622 to 106 mGals. This gravity disturbance value is dominant at $\sim-200$ to -500 mGals. This dominant value lies in the boundary zone of the continental crust with the oceanic crust. On the continental crust, the value of gravity disturbance lies in the range of values $\sim 106$ to - 200 mGals, whereas the oceanic crust zone has a gravity disturbance value of $\sim 500$ to -622 mGals. Based on the value of gravity 
disturbance, it can be analyzed the location of the plate, which is a convergence of the continental crust and oceanic crust. The faults found in the two crusts can also be analyzed using the gravity disturbance approach. The method is done by the extraction of the gravity contour intervals. The selected interval is $50 \mathrm{mGals}$ due to making the visualization more optimal. The results of gravity disturbance contours extraction can be seen in Figure 7.

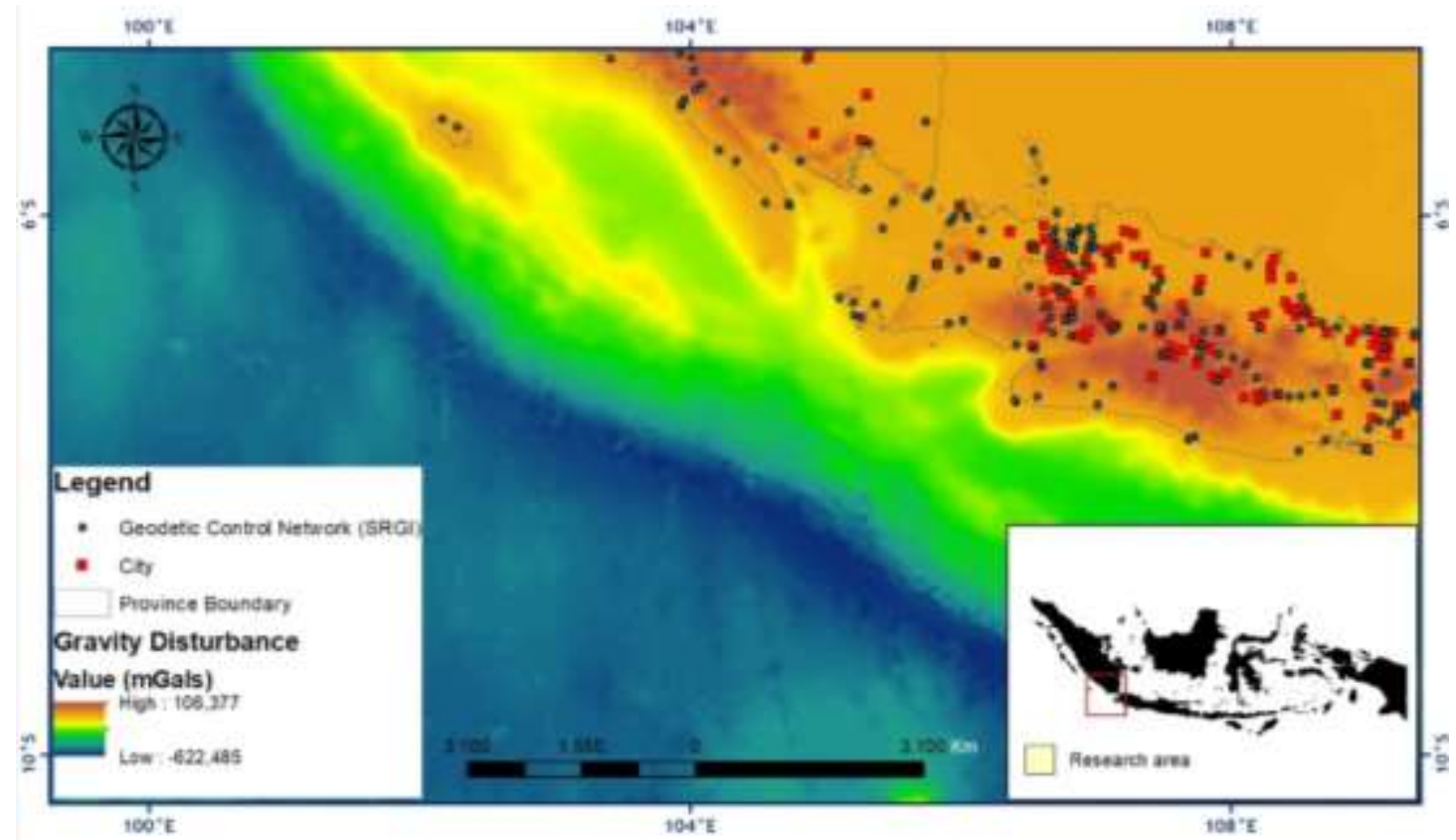

Figure 6. Gravity disturbance in Sunda strait

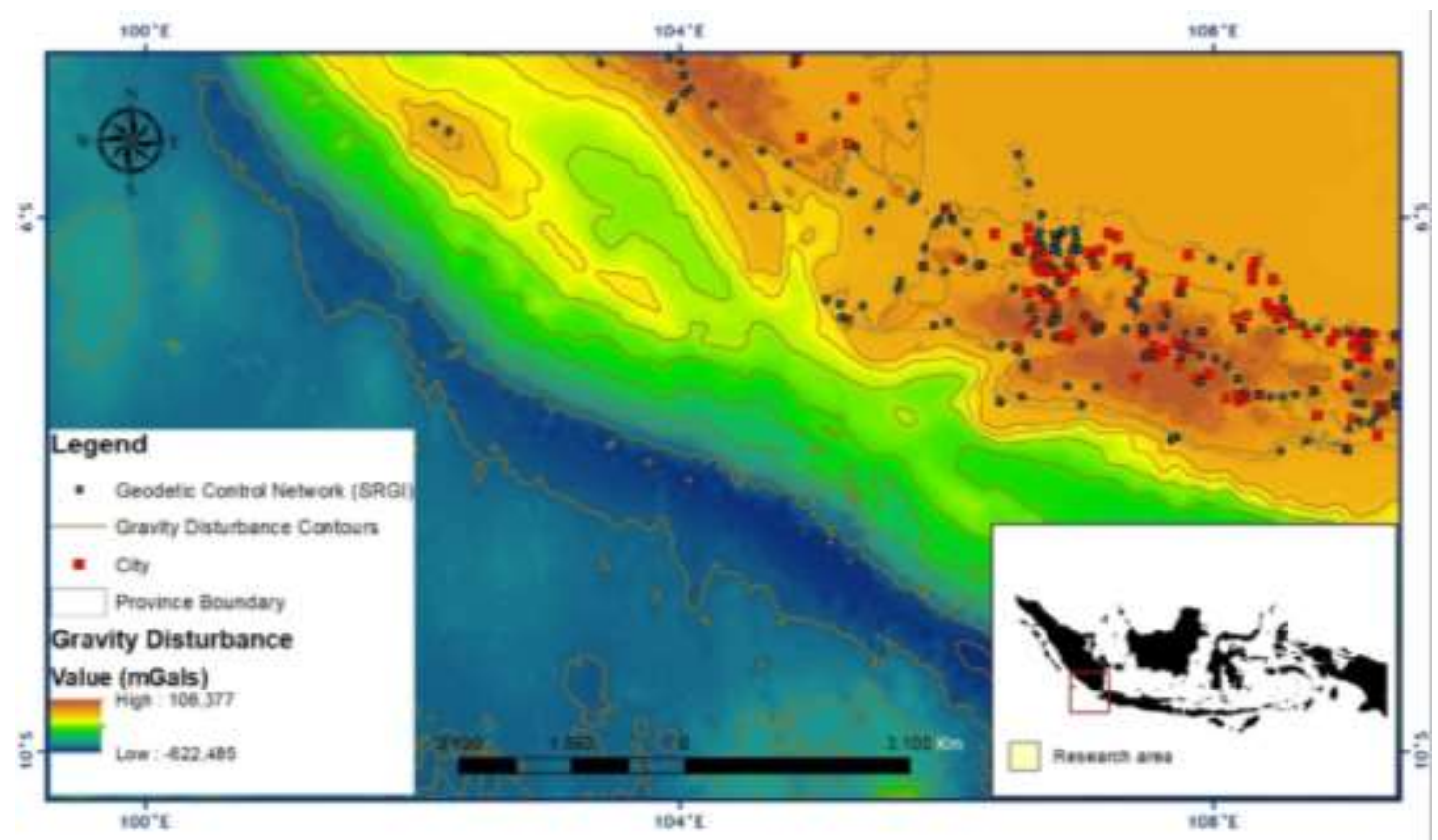

Figure 7. Gravity disturbance contour 


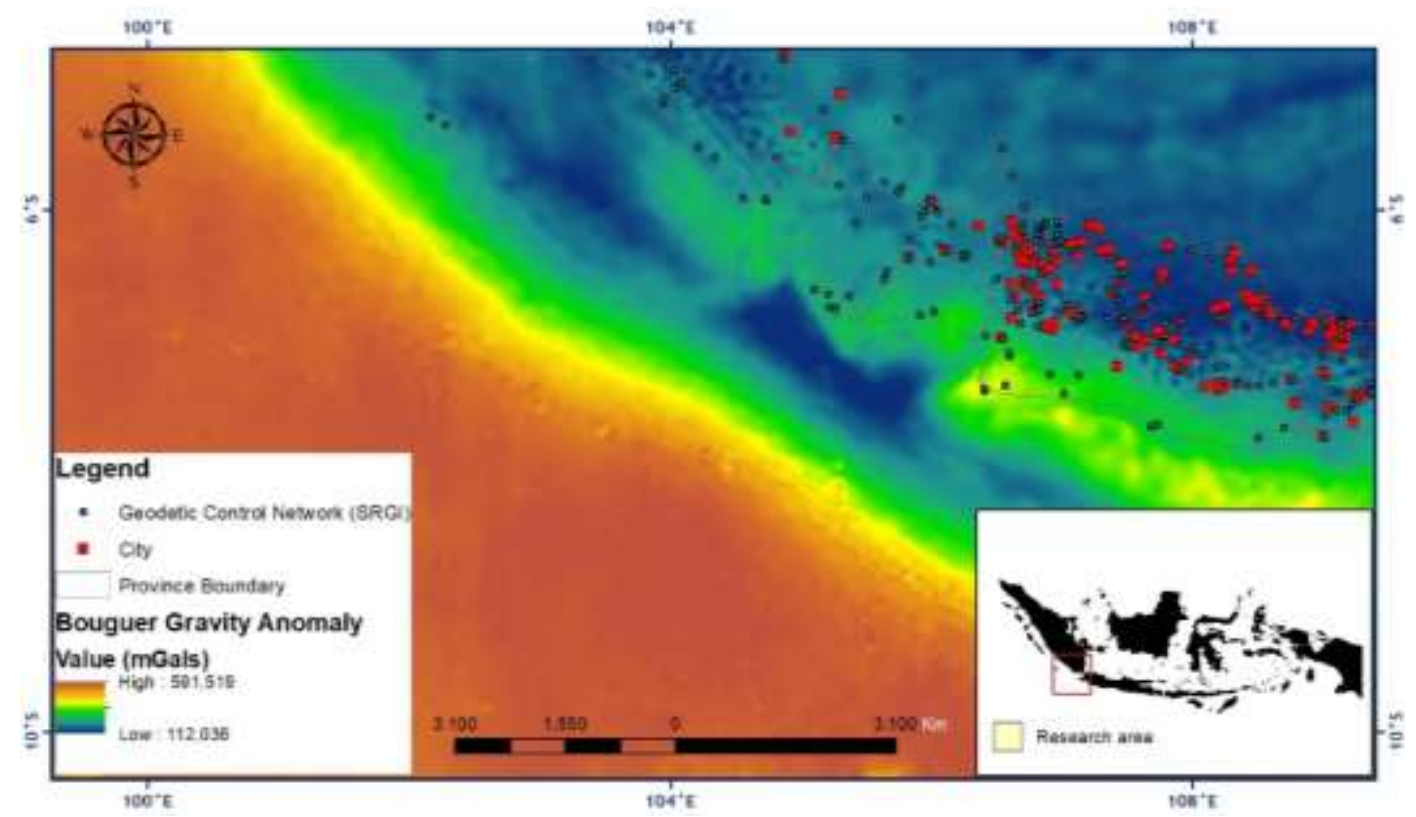

Figure 8. Bouguer gravity anomaly

Visualization of the Bouguer gravity anomaly results can be seen in Figure 8. Gravity disturbance is closer to the plate boundary, megathrust, and fault boundary conditions compared to Bouguer gravity anomaly. Areas of continental and oceanic crust are identified as rocks and non-rocks.

\subsection{Verification of the accuracy assessment}

The verification of the accuracy assessment is using the similarity of two data. Verification of the accuracy assessment on the plate and faults detection uses the gravity disturbance and Bouguer gravity anomaly parameters. Accuracy assessment methods can produce statistical outputs to check the quality of the classification results. The difference between the best and the second-best class assignment is calculated as a percentage. This accuracy assessment uses pattern and texture parameters in detecting the similarity of two or more images.

The results of the visualization were overlaid with plate boundary data, megathrust Sunda and faults data were obtained from the USGS and Ministry of Energy and Mineral Resources. There are differences in the determination of plate boundaries, megathrust, and faults between the results of interpretation from the results of processing from satellites. In the results of processing from satellites in the form of gravity disturbance parameters, it can be seen the details of information and the differences between oceanic crust and continental crust boundaries. The oceanic crust is blue-cyan, while the continental crust is green-yellow-orangebrown. A green-yellow zone is the subduction of the confluence of the plate, see Figure 9.

This accuracy assessment uses similarity data with tolerance in $60 \%$ and a level of confidence $3 \sigma$. Verification of the gravity disturbance is optimal in determining plate boundaries and faults. The accuracy assessment value on plate boundaries and fault lines with gravity disturbance is $83 \%$ for the similarity. The Bouguer gravity anomaly does a similar accuracy assessment. Accuracy assessment using this Bouguer gravity anomaly is better in plate boundaries detection. The accuracy assessment value using the similarity on this plate boundary 
is $83 \%$, see Figure 10 . Fault lines have an accuracy value of $65 \%$. The use of gravity disturbance parameters is optimal in the utilization of plate and fault boundary detection compared to the Bouguer parameter, which is only better in plate boundary detection.

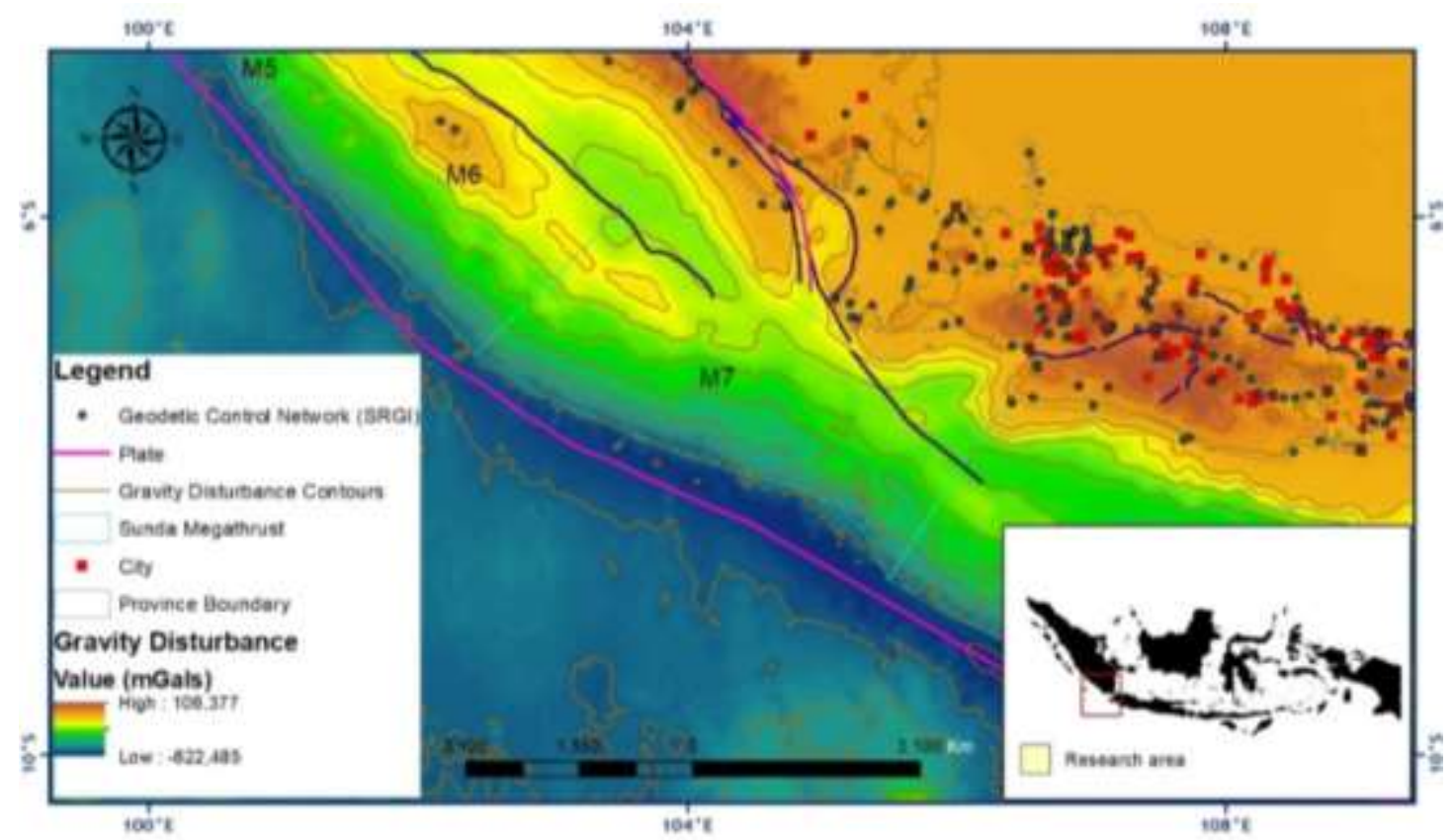

Figure 9. Verification of plate and fault using similarity of gravity disturbance, Bouguer gravity anomaly, and geological data.

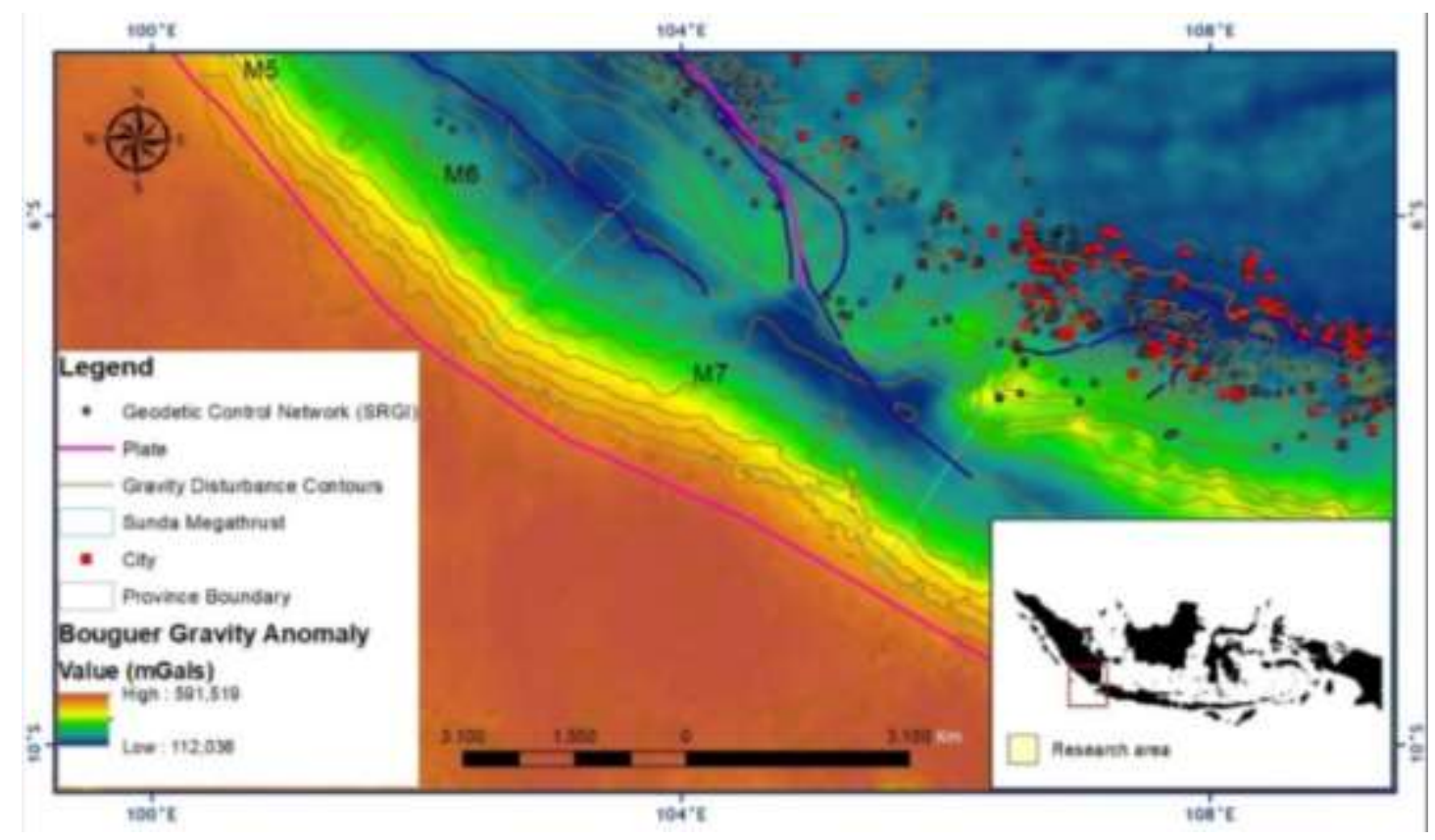

Figure 10. The verification of plate and fault using Bouguer gravity anomaly. 


\subsection{Prospect of Gravity Disturbance for survey and mapping}

The result of plate and faults detection from gravity disturbance can be used for geodesy, geological, and geophysical applications. One of its uses is in faults prediction that has not been detected visually from surface mapping. Besides, the boundaries between the plates obtained are firmer, and the map scale is more extensive than the existing plate boundaries. The result of plate and faults detection can also be used for earthquake monitoring, tsunami simulations, and other geodynamic studies. Following previous literature studies related to GNSS-Leveling and DInSAR, every mapping result obtained from satellite measurements needs validation. The results of the precision plate and faults detection still need to be checked by a geophysical survey and GNSS-Leveling survey in the field to improve its vertical accuracy. Surface deformation, scale deformation, and land subsidence also depend on the level of detail of faults and plates. This research study can be taken into account in the use of deformation monitoring by field measurements, aerial photogrammetry, and satellites.

\section{Conclusions}

This study uses GRACE and GRACE-FO data with the Sunda Strait study area. The results obtained are gravity disturbance and gravity anomaly Bouguer with Barthelmes method approach. Both of these results can be used for plate boundary and faults detection. Plate boundaries are firmer by using gravity disturbance compared to Bouguer gravity anomaly. The faults determination is based on the combination of gravity disturbance and Bouguer gravity anomaly data. The results of plate and faults detection are compared with geological structure data from the USGS and the Indonesian Ministry for Energy and Mineral Resources. The results of plate and faults detection have a high degree of similarity and the map scale is more extensive.

The results of the verification use tolerance in $60 \%$ for its accuracy assessment. The results obtained are the gravity disturbance parameter is more optimal in plate and faults detection than the Bouguer gravity anomaly parameter. The accuracy assessment value on plate boundaries and fault lines with gravity disturbance is $83 \%$. Accuracy assessment using this Bouguer gravity anomaly is better in plate boundaries detection. The accuracy assessment value on this plate boundary is more than $80 \%$. Fault lines have an accuracy value of $65 \%$.

This accuracy assessment can be improved by processing gravity disturbance and Bouguer gravity Anomaly by using geodetic satellite data with higher spatial resolution. Utilizing and integration the multi-data geodetic satellite in gravity anomaly modeling can be used to improve the accuracy. The multi-data geodetic satellite will minimize outliers and will produce more precise plate and faults boundaries. Gravity measurement is needed in the field to find out the true-value accuracy.

\section{Acknowledgment}

The authors would like to thank the BGI, GFZ, dan NASA which had provided free Grace and Grace-FO data. We thank the Universitas Gadjah Mada, Planet, and LAPAN for supporting this research. We thank anonymous reviewers. Atriyon Julzarika contributed in analysis, processing, and modeling the gravity data. Argo Galih Suhadha contributed in processing data, and Indah Prasasti contributed in discussion and writing check. 


\section{References}

Alifa, S. M., Fattah, E. I., \& Munawar Kholil. (2020). Geodetic slip rate and locking depth of east Semangko Fault derived from GPS measurement. Geodesy and Geodynamics, 11(3), 222-228. http://doi.org/10.1016/j.geog.2020.04.002

Balmino, G., \& Bonvalot, S. (2016). Gravity Anomalies. In Encyclopedia of Geodesy (pp. 1-9). Springer. Cham. http://doi.org/10.1007/978-3-319-02370-0

Balmino, G., Vales, N., Bonvalot, S., \& Briais, A. (2012). Spherical harmonic modelling to ultra-high degree of Bouguer and isostatic anomalies. Journal of Geodesy, 86(7), 499-520. http://doi.org/10.1007/s00190-011-0533-4

Barthelmes, F. (2013). Definition of functionals of the geopotential and their calculation from spherical harmonic models: theory and formulas used by the calculation service of the International Centre for Global Earth Models (ICGEM). Scientific Technical Report STR09/02, Revis. Potsdam. http://doi.org/10.2312/GFZ.b1030902-26

Barthelmes, F. (2014). Global Models. In G. E. (Ed.), Encyclopedia of Geodesy (pp. 1-9). Springer International Publishing. http://doi.org/10.1007/978-3-319-02370-0

Bayoud, F. A., \& Sideris, M. G. (2003). Two different methodologies for geoid determination from ground and airborne gravity data. Geophysical Journal International, 155(3), 914-922. http://doi.org/10.1111/j.1365-246X.2003.02083.x

BMKG. (2020). Megathrust Selatan Jawa-Selat Sunda. Jakarta.

Bonvalot, S., Balmino, G., Briais, A., Kuhn, M., Peyrefitte, A., Vales, N., Biance, R., Gabalda, G., Reinquin, F. (2012). World Gravity Map : a set of global complete spherical Bouguer and isostatic anomaly maps and grids. In EGU General Assembly 2012, 22-27 April (p. 11091). Vienna.

Claessens, S. J., \& Hirt, C. (2013). Ellipsoidal topographic potential: New solutions for spectral forward gravity modeling of topography with respect to a reference ellipsoid. JGR Solid Earth, 118(11), 59916002. http://doi.org/10.1002/2013JB010457

Doğru, F., \& Pamukçu, O. (2019). Analysis of gravity disturbance for boundary structures in the Aegean Sea and Western Anatolia. Geofizika, 36(1), 53-76. http://doi.org/10.15233/gfz.2019.36.5

Drewes, H., Kuglitsch, F., Adám, J., \& Rózsa, S. (2016). Geodesy The Handbook. Journal of Geodesy, 90(10), 907-1205. http://doi.org/10.1007/s00190-016-0948-z

ESA. (2020). Grace Satellites. Retrieved from https://earth.esa.int/web/guest/missions/3rd-partymissions/current-missions/grace. European Space Agency

Fukuda, T., Tokuhara, T., \& Yabuki, N. (2016). A dynamic physical model based on a 3D digital model for architectural rapid prototyping. Automation in Construction, 72(Part 1), 9-17. http://doi.org/10.1016/j.autcon.2016.07.002

Grilli, S. T., Tappin, D. R., Carey, S., Watt, S. F. L., Ward, S. N., Grilli, A. R., Engwell, S.L., Zhang, C., Kirby, J.T., Schamarch, L. Muin, M. (2019). Modelling of the tsunami from the December 22, 2018 lateral collapse of Anak Krakatau volcano in the Sunda Straits, Indonesia. Scientific Report, 9, 11946. http://doi.org/10.1038/s41598-019-48327-6

Hani, A. F. M., Sathyamoorthy, D., \& Asirvadam, V. S. (2011). A method for computation of surface roughness of digital elevation model terrains via multiscale analysis. Computer and Geosciences, 37(2), 177-192.

Hanssen, R. F. (2002). Radar Interferometry: Data Interpretation and Error Analysis. Springer Netherlands. http://doi.org/10.1007/0-306-47633-

Hirt, C., \& Kuhn, M. (2012). Evaluation of high-degree series expansions of the topographic potential to higher-order powers. Journal of Geophysical Research, 117(B12), 1-12. http://doi.org/10.1029/2012JB009492

Hirt, C., Kuhn, M., Featherstone, W. E., \& Göttl, F. (2012). Topographic/isostatic evaluation of newgeneration GOCE gravity field models. Journal of Geophysical Research, 117(B5), 10-16. http://doi.org/10.1029/2011JB008878

Hofmann-Wellenhof, B., \& Moritz, H. (2006). Physical Geodesy. Second edition. New York: SpringeWien. 
http://doi.org/10.1007/978-3-211-33545-1

Hurukawa, N., Wulandar, B. R., \& Kasahara, M. (2014). Earthquake history of the Sumatran fault, Indonesia, since 1892, derived from the relocation of large earthquakes. Bulletin of the Seismological Society of America, 104(4), 1750-1762. http://doi.org/10.1785/0120130201

Hutchinson, M., \& Gallant, J. C. (2000). Digital elevation models and representation of terrain shape. In J. P. Wilson \& J. C. Gallant (Eds.), Terrain Analysis: Principles and Applications (pp. 29-50). John Wiley \& Sons.

Ince, E. S., Barthelmes, F., Reißland, S., Elger, K., Förste, C., Flechtner, F., \& Schuh, H. (2019). ICGEM - 15 years of successful collection and distribution of global gravitational models, associated services, and future plans. Earth System Science Data, 11, 647-674. http://doi.org/10.5194/essd-11-647-2019

Julzarika, A. (2015). Height Model Integration using ALOS PALSAR, X SAR, SRTM C, and ICESat/GLAS. International Journal of Remote Sensing and Earth Sciences, 12(2), 107 - 116. http://doi.org/10.30536/j.ijreses.2015.v12.a2691

Julzarika, A., \& Harintaka. (2019). Utilization of Sentinel Satellite for Vertical Deformation Monitoring in Semangko Fault-Indonesia. In The 40th Asian Conference on Remote Sensing (ACRS 2019) October 1418, 2019 / Daejeon Convention Center (DCC), Daejeon. Daejeon, South Korea.

Lanari, R., Mora, O., Manunta, M., Mallorqui, J. J., Berardino, P., \& Sansosti, E. (2004). A small-baseline approach for investigating deformations on full-resolution differential SAR interferograms. IEEE Transactions on Geoscience and Remote Sensing, 42(7), 1377-1386. http://doi.org/10.1109/TGRS.2004.828196

Lasitha, S., Radhakrishna, M., \& Sanu, T. D. (2006). Seismically active deformation in the Sumatra-Java trench-arc region: geodynamic implications. Current Science, 90(5), 690-696. Retrieved from http://www.jstor.org/stable/24089117

Ledoux, H., \& Gold, C. (2005). An Efficient Natural Neighbour Interpolation Algorithm for Geoscientific Modelling. In Development in Spatial Handling (pp. 97-108). Springer Berlin Heidelberg. http://doi.org/10.1007/3-540-26772-7_8

Leick, A., Rapoport, L., \& Tatarnikov, D. (2015). GPS Satellite Surveying (Fourth edition. ed.). United States: John Wiley \& Sons, Inc.

Li, L., \& Kuai, X. (2014). An efficient dichotomizing interpolation algorithm for the refinement of TIN-based terrain surface from contour maps. Computer and Geosciences, 72, 105-121. http://doi.org/10.1016/j.cageo.2014.07.001

McKenzie, D., \& Priestley, K. (2016). Speculations on the formation of cratons and cratonic basins. Earth and Planetary Science Letters, 435, 94-104. http://doi.org/10.1016/j.epsl.2015.12.010

Monserrat, O., Crosetto, M., \& Luzi, G. (2014). A review of ground-based SAR interferometry for deformation measurement. ISPRS Journal of Photogrammetry and Remote Sensing, 93, 40-48. http://doi.org/10.1016/j.isprsjprs.2014.04.001

NASA. (2018). Remote Sensors. Retrieved from https://earthdata.nasa.gov/user-resources/remotesensors. National Aeronautics and Space Administration

Natawidjaja, D. H. (2018). Updating active fault maps and sliprates along the Sumatran Fault Zone, Indonesia. IOP Conference Series: Earth and Environmental Science, 118, 1-11. http://doi.org/10.1088/1755-1315/118/1/012001

Raaflau, L. D., \& J.Collins, M. (2006). The effect of error in gridded digital elevation models on the estimation of topographic parameters. Environmental Modelling \& Software, 21(5), 710-732. http://doi.org/10.1016/j.envsoft.2005.02.003

Sansosti, E., Casu, F., Manzo, M., \& Lanari, R. (2010). Space-borne radar interferometry techniques for the generation of deformation time series: An advanced tool for Earth's surface displacement analysis. Geophysical Research Letters, 37(20), L20305.

Serrano-Juan, A., Pujades, E., Vázquez-Suñèa, E., Crosetto, M., \& Cuevas-González, M. (2017). Leveling vs. InSAR in urban underground construction monitoring: Pros and cons. Case of la sagrera railway station (Barcelona, Spain). Engineering Geology, 218, 1-11. http://doi.org/10.1016/j.enggeo.2016.12.016 
Szostak-Chrzanowski, A. (2006). Interdisciplinary approach to deformation analysis in engineering, mining, and geosciences projects by combining monitoring surveys with deterministic modeling. Part 1. Technical Sciences/University of Warmia and Mazury in Olsztyn, 9, 147-172.

Turcotte, D., \& Schubert, G. (2014). Geodynamics. 3rd edition. Cambridge: Cambridge University Press.

Venera, J., Anton, F., Irina, K., \& Alena, Y. (2016). SAR Interferometry Technique for Ground Deformation Assessment on Karazhanbas Oilfield. Procedia Computer Science, 100, 1163-1167. http://doi.org/10.1016/j.procs.2016.09.271

Yue, T. X., Du, Z. P., Song, D. J., \& Gong, Y. (2007). A new method of surface modeling and its application to DEM construction. Geomorphology, 91(1-2), 161-172. http://doi.org/10.1016/j.geomorph.2007.02.006 